\title{
SOCS-3 negatively regulates innate and adaptive immune mechanisms in acute IL-1-dependent inflammatory arthritis
}

\author{
Peter K.K. Wong, ${ }^{1}$ Paul J. Egan,, ${ }^{1}$ Ben A. Croker, ${ }^{2}$ Kristy O’Donnell, ${ }^{1}$ Natalie A. Sims, ${ }^{3}$ Sarah Drake,, \\ Hiu Kiu, ${ }^{2}$ Edward J. McManus, ${ }^{2}$ Warren S. Alexander, ${ }^{2}$ Andrew W. Roberts, ${ }^{2}$ and lan P. Wicks ${ }^{1}$ \\ ${ }^{1}$ Reid Rheumatology Laboratory, Division of Autoimmunity and Transplantation, and ${ }^{2}$ Cancer and Hematology Division, Walter and Eliza Hall Institute of \\ Medical Research, Parkville, Victoria, Australia. ${ }^{3}$ Department of Medicine, St. Vincent's Hospital, University of Melbourne, Melbourne, Victoria, Australia.
}

\begin{abstract}
RA is an autoimmune disease characterized by sustained imbalance between pro- and antiinflammatory immune mechanisms. The SOCS proteins are negative regulators of cytokine signaling, but to date there has been little information on their function in disease. The generation of Socs $3^{-/ \Delta v a v}$ mice, which lack SOCS-3 in the hematopoietic and endothelial cell compartment, allowed us to explore the role of endogenous SOCS-3

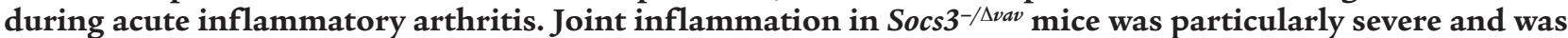
characterized by increased numbers of neutrophils in the inflamed synovium, bone marrow, peripheral blood, and spleen. These features were most likely due to increased production of and enhanced responsiveness to G-CSF and IL-6 during arthritis in these mice. Local osteoclast generation and bone destruction were also dramatically increased in the absence of SOCS-3, as was macrophage activation. Finally, SOCS-3 was found to negatively regulate $\mathrm{CD}^{+} \mathrm{T}$ lymphocyte activation, including production of the pleiotropic cytokine IL-17. The absence of SOCS-3 therefore had dramatic effects in this disease model, with a broader impact on cellular responses than SOCS-1 deficiency. These findings provide direct in vivo evidence that endogenous SOCS-3 is a critical negative regulator of multiple cell types orchestrating inflammatory joint disease.
\end{abstract}

\section{Introduction}

RA is a complex autoimmune disease resulting from sustained imbalance between pro- and antiinflammatory mechanisms (1). IL-1 and TNF are key proinflammatory cytokines implicated in the pathogenesis of RA $(2,3)$. Targeted blockade of IL- 1 and TNF is helpful in RA, but a significant number of patients fail to respond. Therapeutic manipulation of endogenous negative regulators of cytokine signaling might be a more effective therapeutic approach, as this may allow inhibition of multiple cytokines.

The SOCS proteins are key negative regulators of cytokine signaling that inhibit the JAK/STAT signal transduction pathway (4). Production of SOCS proteins may be induced by a wide range of stimuli, including LPS and TNF (5), IL-6 (6), and TGF- $\beta$ (7). Mice lacking individual Socs genes develop different phenotypes. Mice deficient in SOCS-1 died within 2 weeks of age from fatty degeneration and necrosis of the liver and mononuclear cell infiltration into various organs (8). This pathology was dependent on IFN- $\gamma$, as mice lacking both SOCS- 1 and IFN- $\gamma\left(\right.$ SOCS-1 $1^{-1} I F N-\gamma^{-/}$ mice) survived to adulthood (9). The midgestational embryonic lethality in SOCS-3-deficient mice $(10,11)$ has been overcome by a conditional gene-targeting strategy using the cre recombinase (Cre) and loxP system (12). This allowed generation of viable mice following tissue-specific SOCS-3 deletion. Liver-specific deletion of SOCS-3 resulted in prolonged activation of STAT- 3 in hepatocytes following IL- 6 stimulation, indicating that SOCS-3 negatively regulates IL-6 responses in vivo (12). Interestingly,

Nonstandard abbreviations used: Con A, Concanavalin A; IA, intra-articular; mBSA, methylated bovine serum albumin; -R; receptor; rh-, recombinant human; s-, soluble; TRAP, tartrate-resistant acid phosphatase.

Conflict of interest: The authors have declared that no conflict of interest exists. Citation for this article: J. Clin. Invest. 116:1571-1581 (2006). doi:10.1172/JCI25660. in the absence of SOCS-3, IL- 6 also appeared to induce IFN- $\gamma-$ responsive genes $(12,13)$, resulting in antiinflammatory effects $(14,15)$. These findings demonstrate that SOCS-3 may regulate both the quantity and the quality of biologic responses to IL-6. Deletion of SOCS-3 in hematopoietic and endothelial cells $\left(\operatorname{Socs}^{-/ \Delta v a v}\right)$ resulted in dysregulated hematopoiesis characterized by peripheral blood neutrophilia, enhanced BM myelopoiesis and splenomegaly, and marked extramedullary hematopoiesis from the age of 17 weeks (16). Socs $3^{-/ \Delta v a v}$ mice exhibited prolonged STAT-3 activation, increased frequency of clonogenic neutrophil progenitors, and enhanced survival and proliferation of mature granulocytes following in vitro stimulation with G-CSF.

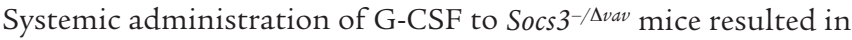
peripheral neutrophilia, splenomegaly, and neutrophil infiltrates in multiple tissues, indicating that SOCS-3 is also a key negative regulator of G-CSF signaling (16).

Intriguingly, SOCS-3 dysregulation may be specifically associated with joint disease. Mice with a mutation in the transmembrane receptor gp130 (Y757F mice), which ablates the SOCS-3 binding site, developed a spontaneous RA-like phenotype with advanced age (17). Mice expressing a knock-in mutation (gp130 $\left.{ }^{\triangle \mathrm{STAT}}\right)$ that eliminated STAT-1 and -3 signaling developed a joint disease composed of both inflammatory and degenerative features (18). Impaired SOCS-3 induction following signaling through gP130 $13 \mathrm{STAT}$ was associated with overactivation of the SHP-2/ras/ERK pathway in these mice, which appeared to cause hyper-proliferation of synovial fibroblasts and chondrocytes (ref. 18 and our unpublished observations). SOCS-3 expression has been reported in synovial tissue from mice during experimental arthritis and in patients with RA (19). Intra-articular (IA) ankle injections of recombinant adenovirus expressing SOCS-3 reduced joint inflammation in experimental models of arthritis, 

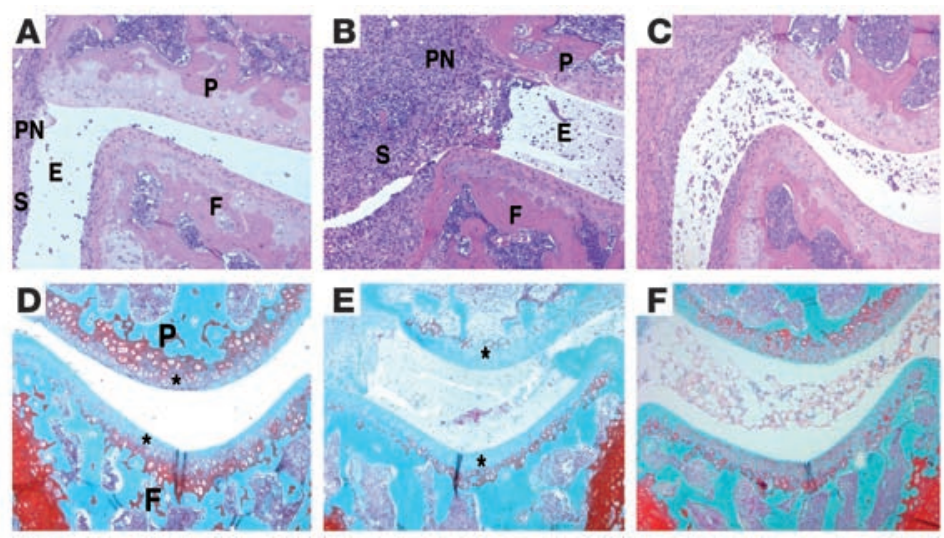

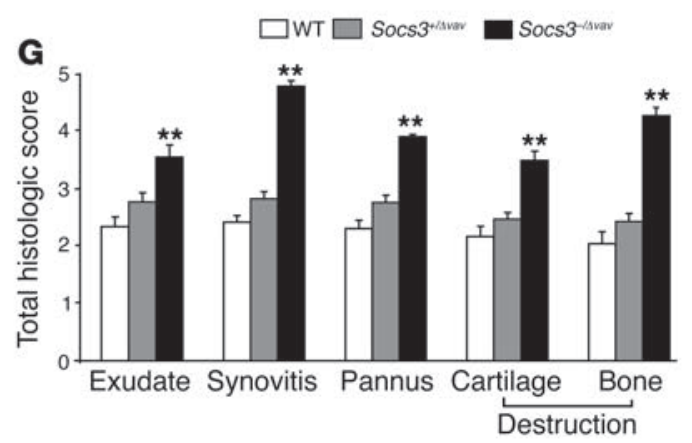

Figure 1

SOCS-3 deficiency is associated with exacerbated mBSA/IL-1-induced arthritis. (A-F) Acute inflammatory arthritis was induced by IA injection of $200 \mu \mathrm{g} \mathrm{mBSA}$ into the knee joint followed by 3 daily subcutaneous injections of $250 \mathrm{ng}$ rhlL-1. Mice were sacrificed on day 7 , and knee joints were processed as described in Methods. Frontal H\&E-stained sections through knee joints from arthritic WT (A) and Socs3-/Avav (B) mice. S, synovitis; F, femur; E, exudate; PN, pannus; P, patella. (C) Representative section from an arthritic SOCS-1-l-IFN- $\gamma^{-1-}$ mouse (25) using the same disease model is shown for comparison. Frontal Safranin O-stained sections through arthritic knee joints from a WT mouse (D) showing mild proteoglycan loss (asterisk indicates loss of red staining), while the Socs3-/Lvav joint (E) had marked proteoglycan loss. (F) Arthritic knee joint from a SOCS-1--IFN- $\gamma^{-1-}$ mouse is shown for comparison. Magnification, $\times 200(\mathbf{A}-\mathbf{C}) ; \times 400$ (D-F). (G) Joint sections were graded for 5 features of inflammatory arthritis, each on a scale of 0 (normal) to 5 (severe) by an investigator blinded to the experimental groups. Results shown are the mean \pm SEM for $16-19$ joints per group, pooled from 3 separate experiments. ${ }^{\star \star} P<0.01$ versus WT and Socs $3^{+/ \Delta v a v}$.

a result associated with decreased STAT-3 phosphorylation and IL-6 production (19). However, the role of endogenous SOCS-3 in experimental arthritis has not been previously examined.

In RA, joint inflammation and damage results from interaction between hematopoietically derived immune cells and resident cells of joints such as synovial fibroblasts and chondrocytes (20). In order to evaluate the role of SOCS-3 in regulation of the cellular and molecular mediators implicated in inflammatory joint disease, we therefore induced inflammatory arthritis in mice that had undergone deletion of SOCS-3 in all hematopoietic and endothelial cells. This overcame the limitation of embryonic lethality following complete SOCS-3 deletion but also allowed us to examine the contribution of SOCS- 3 in regulating cellular responses to joint inflammation.

We used a model of acute inflammatory arthritis that is dependent on IA antigen (methylated bovine serum albumin [mBSA]) and $\mathrm{CD}^{+} \mathrm{T}$ lymphocytes (21). IL-1 is a major mediator of RA (2, 22 ), and systemic injection of IL-1 in mice converts the transient $\mathrm{CD}^{+} \mathrm{T}$ lymphocyte-dependent inflammatory reaction to $\mathrm{mBSA}$ into a florid monoarthritis. Synovial macrophages, neutrophils, G-CSF, and IL- 6 are also important mediators of pathology in this model $(23,24)$. While no one model of arthritis can completely reproduce the complexity of RA in humans, the strengths of this disease model are the high incidence of arthritis in injected knee joints; the rapid, reproducible disease kinetics; and the relatively well-defined molecular and cellular mediators. As such, this model provides insight into the earliest stages of the joint inflammation that occurs in RA.

We have previously used this model to examine the role of SOCS-1 (25), the p50 subunit of NF-кB (20), and TNF (26) in inflammatory arthritis. SOCS-1 $1^{-/-} I F N-\gamma^{-/}$mice developed more severe arthritis compared with SOCS-1 $1^{+/} I F N-\gamma^{-/-}$mice (25), and this was associated with an increased number of macrophages in the synovium and joint exudate, synovial granulomas, and lymph- adenopathy of draining (popliteal) LNs. In contrast, there was only a small increase in synovial neutrophil numbers and osteoclastmediated bone destruction in arthritic SOCS $-1^{-/-I F N-\gamma^{-/-}}$mice. SOCS-1 promoter activity was found in synovial macrophages, fibroblasts, and activated $\mathrm{T}$ lymphocytes but not synovial granulocytes, consistent with a SOCS-1-mediated response in these cells to cytokine stimulation during arthritis.

We now show that mBSA/IL-1-dependent arthritis was markedly exacerbated following SOCS-3 deletion in hematopoietic and endothelial cells. However, in contrast to SOCS-1 deficiency, the severe joint inflammation occurring in the absence of SOCS-3 was characterized by increased numbers of neutrophils in the inflamed synovium, peripheral blood, and spleen, most likely due to hyperresponsiveness to G-CSF and IL-6 but possibly due to IL-1 directly. SOCS-3 was also found to be an important negative regulator of $\mathrm{CD}^{+} \mathrm{T}$ lymphocyte and macrophage activation and osteoclast generation. These findings provide the first in vivo evidence to our knowledge that endogenous SOCS-3 is a critical negative regulator of the multiple cell types mediating inflammatory joint disease and suggest that SOCS-3 regulates an even wider range of cellular responses than does SOCS-1 during inflammatory arthritis.

\section{Results}

Socs $3^{-/ \Delta v a v}$ mice develop exacerbated inflammatory arthritis. To assess the role of endogenous SOCS-3 in the pathogenesis of inflammatory arthritis, we compared the severity of mBSA/IL-1-induced arthritis in WT and Socs $3^{+/ \Delta v a v}$ mice as well as Socs $3^{-/ \Delta v a v}$ mice, which have undergone deletion of SOCS-3 in all hematopoietic and endothelial cells. Knee joints were processed for histology on day 7 following mBSA injection, and sections were graded by an investigator blinded to the treatment groups. Socs $3^{-/ \Delta v a v}$ mice developed markedly worse disease than age-, sex- and strain-matched WT and

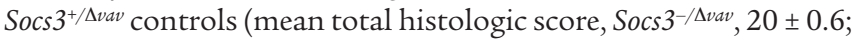
WT, $11.3 \pm 0.7 ;$ Socs $^{+/ \Delta v a v}, 13.3 \pm 0.6 ; P<0.01$, Socs3 ${ }^{-/ \Delta v a v}$ versus WT 

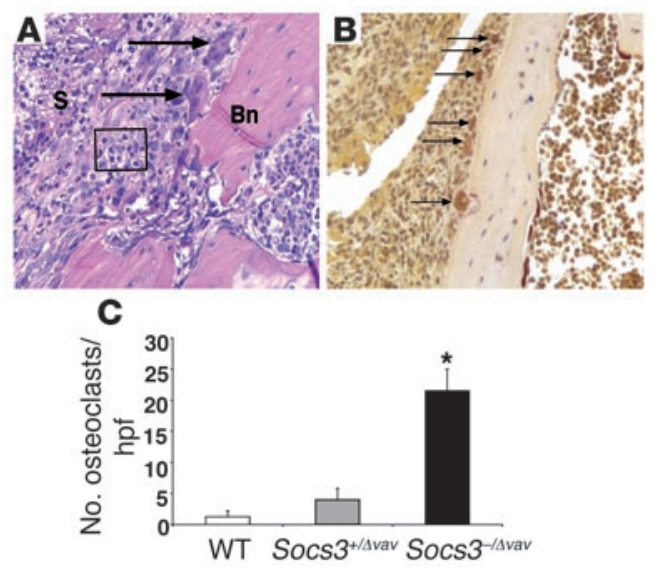
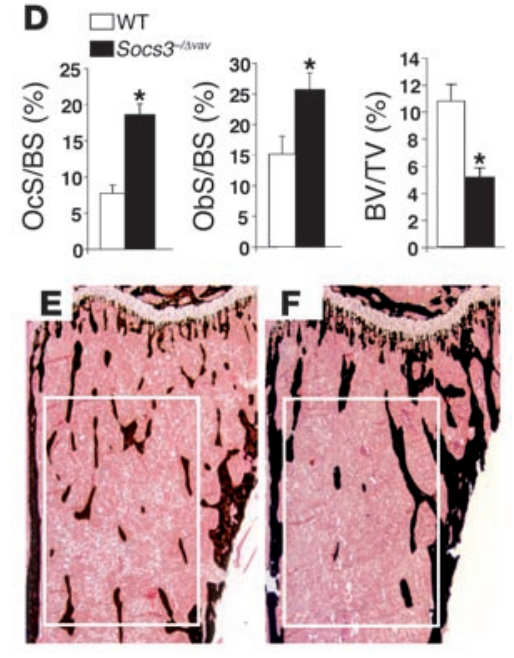

\section{Figure 2}

SOCS-3 deficiency is associated with increased osteoclast numbers. (A and B) Frontal sections through an arthritic Socs3-/Avav knee joint showing H\&E-stained synovitis (S) containing numerous granulocytes (boxed area) with several multinucleated osteoclasts (large arrows) eroding into bone (Bn; A) and TRAP-stained osteoclasts (small arrows; B). (C) TRAP+ cells on the periosteal surfaces of arthritic joints per high-power field (hpf) were counted by an investigator blinded to the experimental groups (mean \pm SEM; $n=5$ mice per group, pooled from 2 independent experiments). (D) Histomorphometry was performed by an investigator blinded to the experimental groups. OcS/BS, ratio of osteoclast surface to bone surface; ObS/Bs, ratio of osteoblast surface to bone surface; BV/TV, trabecular bone volume. Values are mean $\pm \mathrm{SEM}$; $n=8-10$ male mice per group at 8-12 weeks of age. Similar findings were seen in female mice. ( $E$ and $\mathbf{F}$ ) Representative images of von Kossa-stained tibiae of male 8-week-old WT (E) and Socs3 ${ }^{-/ \Delta v a v}(\mathbf{F})$ mice showing differences in trabecular bone volume. White boxes show secondary spongiosa region used for histomorphometric measurements. Magnification, $\times 400$ (A and B); $\times 100$ (E and F). ${ }^{*} P<0.05$ versus WT and Socs $3^{+/ \Delta v a v}$.

and Socs3 $3^{+/ \Delta v a v}$; Figure 1, A, B, and G). Socs3 $3^{-/ \Delta v a v}$ mice had dramatic synovial hyperplasia and aggressive pannus eroding into bone with increased inflammatory exudate. No synovial granulomas were seen in arthritic Socs $3^{-/ \Delta v a v}$ mice, unlike those seen in arthritic

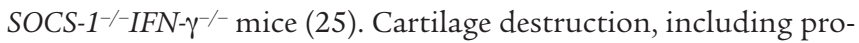
teoglycan loss, was substantially increased in Socs3-/Avav mice (compare Figure 1E with Figure 1, D and F; also see Figure 1G). These findings indicate that endogenous SOCS-3 is an important negative regulator of $\mathrm{mBSA} / \mathrm{IL}-1$-dependent inflammatory arthritis.

Socs $3^{-/ \Delta v a v}$ mice have exacerbated bone destruction, reduced basal trabecular bone volume, and increased osteoclast numbers during joint inflammation. Bone destruction was significantly worse in arthritic Socs $3^{-/ \Delta v a v}$ mice compared with WT and Socs $3^{+/ \Delta v a v}$ controls and was characterized by prominent osteoclasts (Figure $1 \mathrm{G}$ and Figure 2, A and $\mathrm{B}$ ). When osteoclasts, which are not usually a prominent feature of $\mathrm{mBSA} / \mathrm{IL}-1$-induced arthritis, were identified by tartrateresistant acid phosphatase (TRAP) staining, Socs $3^{-/ \Delta v a v}$ mice had approximately 10 -fold more osteoclasts present on the periosteal surfaces compared with controls (Figure 2C). This led us to investigate bones in naive $\operatorname{Socs} 3^{-/ \Delta v a v}$ mice. Histomorphometric analysis showed that the percentage of trabecular bone covered by osteoclasts (osteoclast surface/bone surface) within the secondary spongiosa was tripled in naive male Socs $3^{-/ \Delta v a v}$ mice (Figure $\left.2 \mathrm{D}\right)$. The ratio of osteoblast surface to bone surface was doubled in naive Socs $3^{-/ \Delta v a v}$ mice, indicating that enhanced basal bone resorption in Socs $3^{-/ \Delta v a v}$ mice was associated with increased bone formation in vivo. These findings were associated with a $50 \%$ reduction in tra-

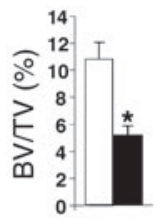

becular bone volume in adult male mice as assessed by histomorphometry (Figure 2, D-F). Similar effects were present but were less dramatic in female mice (data not shown), probably because trabecular bone volume is generally lower in female mice (27). These findings suggest that endogenous SOCS-3 is an important regulator of osteoclastogenesis both in the basal state and during inflammation.

Increased infiltration of neutrophils into the synovium in arthritic Socs $3^{-/ \Delta v a v}$ mice. To characterize the synovial inflammatory cell infiltrate, we prepared singlecell suspensions of synovial tissue by enzymatic digestion. Hematopoietic cells were identified by expression of CD45 and further characterized by staining with antibodies specific for CD $11 \mathrm{~b}$ and GR-1. The percentage of neutrophils, as defined by expression of both CD11b and GR-1 among the CD45-gated population of synovial cells, increased from approximately $20 \%$ in WT and Socs $3^{+/ \Delta v a v}$ mice to $44 \%$ in Socs $3^{-/ \Delta v a v}$ mice, with a corresponding fall in the percentage of CD $11 b^{+}$GR-1- cells (macrophages) from over $60 \%$ in WT and Socs $3^{+/ \Delta v a v}$ mice to

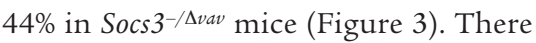
was no difference in the percentages of $\mathrm{CD}^{+}, \mathrm{CD}^{+}$, or $\mathrm{B} 220^{+}$cells in inflamed synovium from Socs $3^{-/ \Delta v a v}$ mice compared with their respective controls (data not shown). These findings suggest that SOCS-3 particularly regulates the neutrophil contribution to acute inflammatory arthritis.

Acute arthritis in Socs3-/Avav mice is accompanied by increased numbers of neutrophils in peripheral blood, spleen, and bone marrow. Given the elevated numbers of neutrophils in arthritic synovium of Socs $3^{-/ \Delta v a v}$ mice, we investigated whether there were elevated neutrophil numbers in other tissue compartments. The peripheral blood counts of Socs $3^{-/ \Delta v a v}$ and Socs $3^{+/ \Delta v a v}$ mice without arthritis are normal (16). There was a 5 -fold increase in neutrophil numbers in the peripheral blood of Socs $3^{-/ \Delta v a v}$ mice following mBSA/IL-1induced arthritis on day 7 compared with WT and Socs $3^{+/ \Delta v a v}$

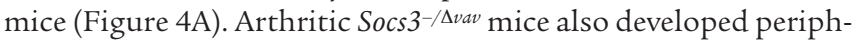
eral blood thrombocytosis (mean platelet count, Socs $3^{-/ \Delta v a v}$, $2,088 \pm 178 \times 10^{9}$ cells $/ 1$; WT, $1,229 \pm 286 \times 10^{9}$ cells $/ 1 ; n=4$ mice per group; $P<0.05)$. In contrast, there was no difference in other peripheral blood lineages in arthritic Socs $3^{-/ \Delta v a v}$ mice compared with arthritic WT and Socs $3^{+/ \Delta v a v}$ mice (data not shown).

Socs $3^{-/ \Delta v a v}$ mice also developed splenomegaly following $\mathrm{mBSA} /$ IL-1-induced arthritis (Figure 4B). Spleens from Socs $3^{-/ \Delta v a v}$ mice had markedly disordered architecture with loss of delineation between white and red pulp due to infiltration of inflammatory cells (Figure 4, C and D). To determine the phenotype of inflammatory cells in the spleen following arthritis induction, single-cell suspensions of splenic tissue were stained for flow cytometry. The percentage of neutrophils (CD $11 \mathrm{~b}^{+} \mathrm{GR}-1^{+}$cells) increased from less than $10 \%$ of cells in spleens from arthritic WT and Socs $3^{+/ \Delta v a v}$ mice to over $40 \%$ in Socs $3^{-/ \Delta v a v}$ mice (Figure 4E). The percentages 


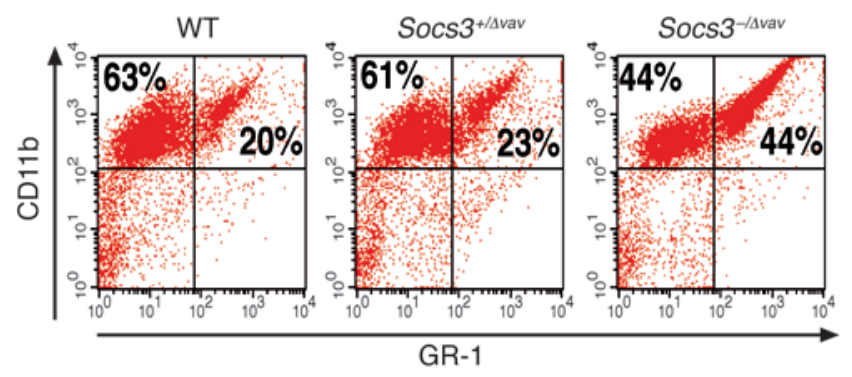

Figure 3

Accumulation of neutrophils (CD11b+GR-1+ cells) in the synovium of Socs3-/Avav mice during acute arthritis. Synovium was dissected from knee joints of arthritic mice on day 7 after arthritis induction. Pooled synovial cells from 5 mice per group were isolated by enzymatic digestion and stained for expression of CD45, CD11b, and GR-1. Analysis of CD11b and GR-1 expression was performed on CD45+ cells. Results shown are representative of 3 independent experiments. Percentages in top left and right boxes indicate the percentage of CD11b+GR-1- and CD11b+GR $-1+$ cells, respectively.

of $\mathrm{CD}^{+}, \mathrm{CD}^{+}$, and $\mathrm{B} 220^{+}$cells were reduced due to the increased proportion of CD $11 \mathrm{~b}^{+} \mathrm{GR}-1^{+}$cells in spleens of arthritic Socs $3^{-/ \Delta v a v}$ mice. There was no difference in the percentage of monocytes/

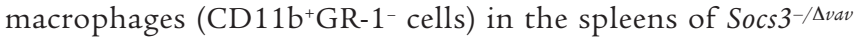
mice compared with control mice.

Given the increased numbers of neutrophils in peripheral blood and spleen, we next examined the BM. The percentage of neutrophils (CD $11 \mathrm{~b}^{+} \mathrm{GR}-1^{+}$cells) in BM increased from approximately $50 \%$ of cells from arthritic WT and Socs $3^{+/ \Delta v a v}$ mice to $69 \%$ in Socs $3^{-/ \Delta v a v}$ mice (Figure 4F). While naive Socs $3^{-/ \Delta v a v}$ mice older than 17 weeks develop splenomegaly due to neutrophil accumulation and increased BM granulopoiesis (16), this does not occur in younger mice. We were careful to use Socs $3^{-/ \Delta v a v}$ mice aged 8-12 weeks to avoid this age-related phenotype.

Deletion of SOCS-3 therefore appears to result in articular and extra-articular effects in this disease model. In contrast to arthritis occurring in the absence of SOCS-1, exacerbated acute arthritis in Socs $3^{-/ \Delta v a v}$ mice was characterized by markedly increased numbers of neutrophils in the synovium, peripheral blood, spleen and BM.

Elevated serum levels of G-CSF and IL-6 in arthritic Socs3-/Dvav mice. SOCS-3 regulates G-CSF (16) and IL-6 (12) signaling in vivo, and both these cytokines are implicated in mBSA/IL-1-induced arthritis $(23,24)$. While G-CSF is the main regulator of granulocyte production (28-30), IL-6 may also be involved (31, 32). Given the increased numbers of neutrophils in the synovium, blood,

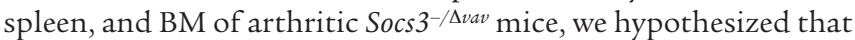
systemic levels of G-CSF and IL- 6 might be elevated. Arthritic

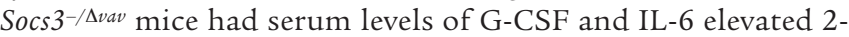
and 20 -fold, respectively (Table 1 ).

Arthritic Socs $3^{-/ \Delta v a v}$ mice develop enlarged draining LNs. Since mBSA/ IL-1-induced arthritis is dependent on T lymphocytes, we examined the phenotype of cells within draining LNs on day 7 following arthritis induction. Because of the small size of individual popliteal LNs, results shown represent average LN size calculated from pooled LN cells. In 2 independent experiments, there were

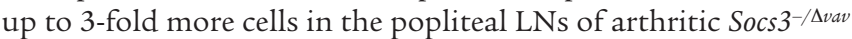

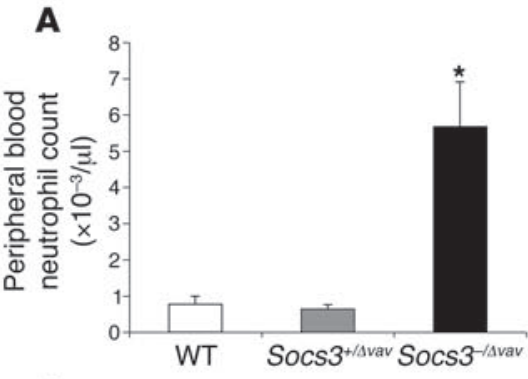

E

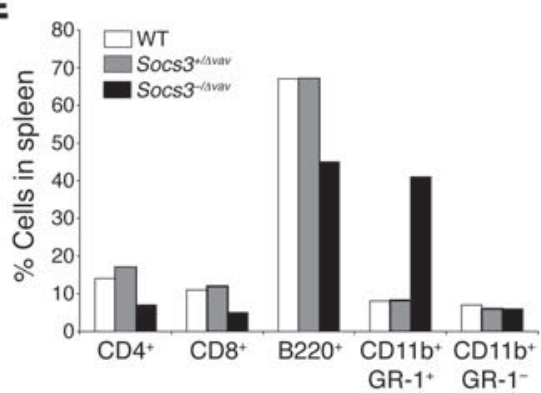

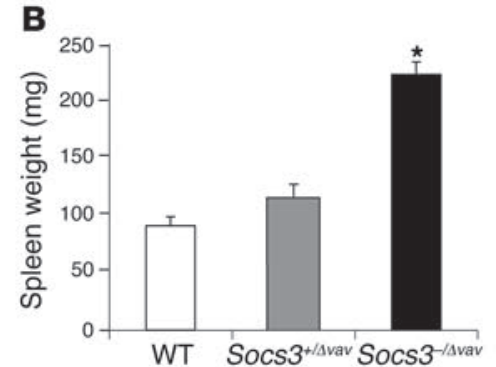
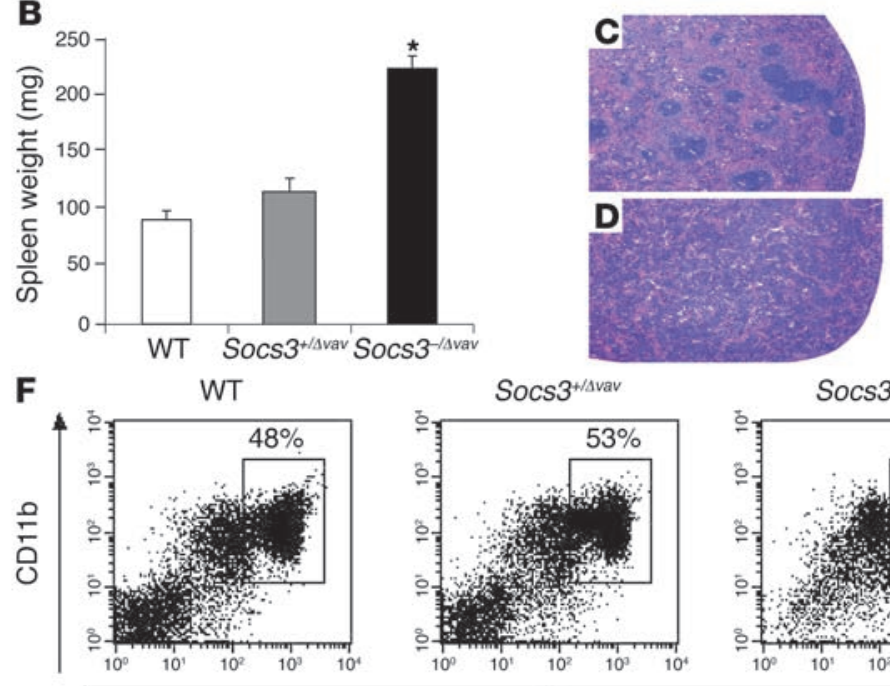

WT
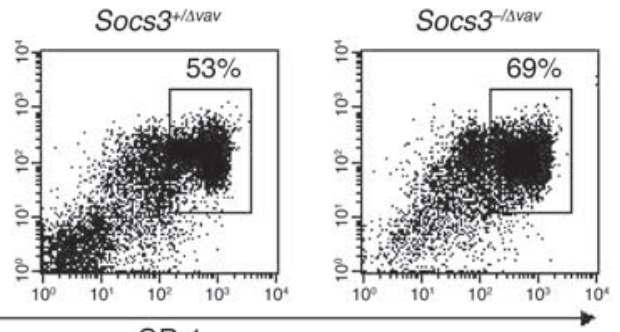

GR-1

\section{Figure 4}

Acute inflammatory arthritis in Socs3-/Avav mice is accompanied by peripheral blood neutrophilia, splenomegaly, and increased granulopoiesis. (A) Peripheral blood from arthritic mice at day 7 was analyzed on an automatic cell analyzer. Mean \pm SEM cell counts pooled from 2 independent experiments are shown ( $n=7-10$ mice per group). (B) Mean \pm SEM spleen weights of arthritic mice from 2 independent experiments are shown ( $n=4-7$ spleens per group). (C and D) Histologic sections through H\&E-stained spleens from arthritic WT (C) and Socs3 ${ }^{-/ \Delta v a v}$ (D) mice aged 8-12 weeks showing loss of delineation between white and red pulp in the Socs3-/svav spleen due to infiltrating granulocytes. Magnification, $\times 100$. (E) Spleen cells were stained with FITC- or PE-conjugated antibodies to CD4, CD8, B220, CD11b, or GR-1. (F) BM cells from arthritic mice were stained with FITC- or PE-conjugated antibodies to GR-1 and CD11b. Percentages above boxed regions (demonstrating CD11b+GR-1+ area) indicate the percentage of neutrophils. ${ }^{*} P<0.05$ versus WT and Socs3 ${ }^{+/ \Delta v a v}$. 
Table 1

Acute arthritis in Socs3-Avav mice is accompanied by elevated serum levels of G-CSF and IL-6

\begin{tabular}{|c|c|c|}
\hline & G-CSF (pg/ml) & IL-6 (pg/ml) \\
\hline Socs3- $3^{-\Delta v a v}$ & $2215 \pm 480^{A}$ & $50.4 \pm 19^{A}$ \\
\hline WT & $1178 \pm 100$ & $2.6 \pm 2.6$ \\
\hline
\end{tabular}

Mean \pm SEM serum levels of G-CSF ( $n=4-6$ mice per group) and IL-6 ( $n=5-8$ mice per group) from arthritic Socs3-/Lvav and WT mice were determined by ELISA. ${ }^{A} P<0.05$ versus WT.

mice compared with WT controls (Figure 5A). There was a 4-fold increase in absolute number of B lymphocytes $\left(\mathrm{B} 220^{+}\right.$cells $)$and a 2 -fold increase in $\mathrm{CD}^{+}$and $\mathrm{CD}^{+} \mathrm{T}$ lymphocytes in popliteal LNs

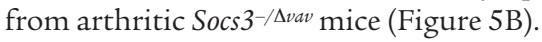

Socs3-/Avav $L N$ cells hyperproliferate and produce more $I L-17$ in vitro. One possible explanation for the observed hypercellularity of

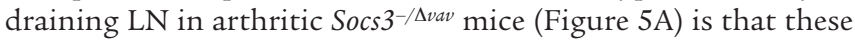
LN cells are hyperresponsive to cytokines produced following IA antigen injection. In order to test this, draining (popliteal) and nondraining (axillary) LN cells from arthritic mice were cultured in the presence of mBSA for 72 hours, and cellular proliferation was assessed by $\left[{ }^{3} \mathrm{H}\right]$ thymidine incorporation. While popliteal or axillary LN cells from WT mice showed low-level proliferation in vitro in response to $\mathrm{mBSA}$, as previously reported (21), popliteal and axillary LN cells from Socs $3^{-/ \Delta v a v}$ mice proliferated strongly following mBSA stimulation (Figure 6, A and B). Overall, proliferation of popliteal LN cells from Socs $3^{-/ \Delta v a v}$ mice was increased up to 100-fold compared with cells from WT and Socs $3^{+/ \Delta v a v}$ mice. Cells from Socs $3^{-/ \Delta v a v}$ axillary LNs, which do not directly drain the knee, proliferated up to 20 -fold more than did WT or Socs $3^{+/ \Delta v a v}$ cells in response to mBSA. In addition, popliteal and axillary LN

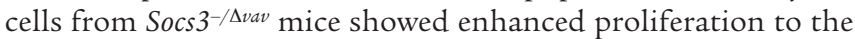
nonspecific mitogen Concanavalin A (Con A) and in the absence of exogenous antigen, possibly due to increased sensitivity of these activated cells to autocrine cytokine stimulation.

Osteoclasts and bone destruction were prominent features of the inflammatory arthritis seen in Socs $3^{-/ \Delta v a v}$ but not WT mice (Figure 2, A-C). IL-17 is produced by T lymphocytes and has been shown to promote osteoclastogenesis (33). Given the increased antigen-specific mitogenic response of draining LN cells, we hypothesized that greater IL-17 production by T lymphocytes might contribute to enhanced osteoclastogenesis. Following mBSA stimulation, Socs $3^{-/ \Delta v a v} \mathrm{~T}$ lymphocytes produced markedly elevated levels of IL-17 (Figure 6C). In comparison, IL-17 was undetectable in supernatants from WT cultures. There was no

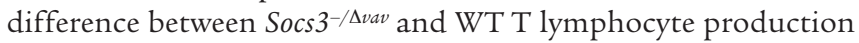
of IL-17 following Con A stimulation (Figure 6C), demonstrating that this was an antigen-specific effect.

SOCS-3 deficiency therefore results in hyperactive $T$ lymphocytes and enhanced antigen-specific proliferation. Strong proliferative responses from axillary LNs were also noted, probably following trafficking of activated $\mathrm{T}$ lymphocytes. These findings suggest that SOCS-3 is an important regulator of T lymphocyte expansion following antigenic stimulation. Activated T lymphocyte production of IL-17 may also promote local osteoclastogenesis and thereby contribute to bone destruction.

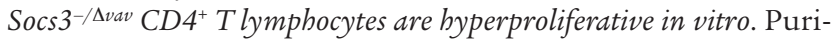
fied $\mathrm{CD}^{+} \mathrm{T}$ lymphocytes from naive Socs $3^{-/ \Delta v a v}$ and WT mice were cultured with immobilized anti-CD3 to evaluate whether the absence of SOCS-3 resulted in increased proliferation following $\mathrm{T}$ cell receptor stimulation. Socs $3^{-/ \Delta v a v} \mathrm{CD} 4^{+} \mathrm{T}$ lymphocytes had up to 3 -fold increases in proliferation and IL-2 production compared with WT cells following stimulation with anti-CD3 (Figure 7, A and B).

mBSA/IL-1-induced arthritis is dependent on $\mathrm{CD}^{+} \mathrm{T}$ lymphocytes (21) and is driven by exogenous IL-1. However, G-CSF (23) and IL-6 (24) are important proinflammatory mediators in this model. Cells lacking SOCS-3 are hyperresponsive to these cytokines $(12,16)$, and $\mathrm{T}$ lymphocytes express receptors for both G-CSF (34) and IL-6 (35). We therefore investigated whether CD4+ $\mathrm{T}$ lymphocytes from naive Socs $3^{-/ \Delta v a v}$ and WT mice were hyperresponsive to stimulation with IL-1, IL-6, or G-CSF. Purified CD4 ${ }^{+}$ T lymphocytes (>90\% purity) were cultured in the presence of IL-1, IL-6 (with soluble IL-6 receptor; sIL-6R), and G-CSF. Socs3-/4vav $\mathrm{CD}^{+} \mathrm{T}$ lymphocytes had a 2 -fold greater mitogenic response in the absence of exogenous cytokine (Figure 7C). Following 24 hours of stimulation with these cytokines, naive Socs $3^{-/ \Delta v a v} \mathrm{CD}^{+} \mathrm{T}$ lymphocytes had up to 4-fold greater proliferation compared with WT CD $4^{+}$T lymphocytes (Figure 7C).

SOCS-3 therefore appears to be involved in regulation of naive and activated $\mathrm{CD}^{+} \mathrm{T}$ lymphocyte proliferative responses following $\mathrm{T}$ cell receptor-mediated activation. SOCS-3 may also regulate in vivo $\mathrm{T}$ lymphocyte proliferative responses following bystander stimulation with proinflammatory cytokines such as IL-1, G-CSF, and IL-6.

Hyperresponsiveness of Socs $3^{-/ \Delta v a v}$ macrophages to IL-1. During inflammatory joint disease, macrophages are an important source of proinflammatory cytokines such as TNF and IL-1 (36), IL-6 (37), and G-CSF (38). Synovial macrophages are required for mBSA/IL-1-
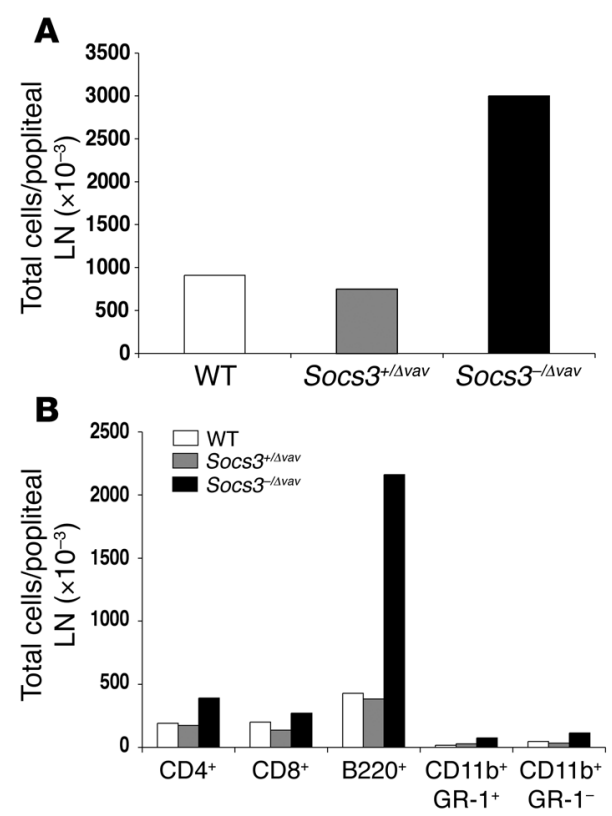

Figure 5

Acute arthritis in Socs3-/Avav mice is accompanied by enlarged draining LN. (A) Cell counts of popliteal LN harvested from arthritic mice on day 7 following arthritis induction, pooled from 2 independent experiments. (B) Single-cell suspensions of popliteal LN tissue were stained with FITC- or PE-conjugated antibodies to CD4, CD8, B220, CD11b, and GR-1. 
A

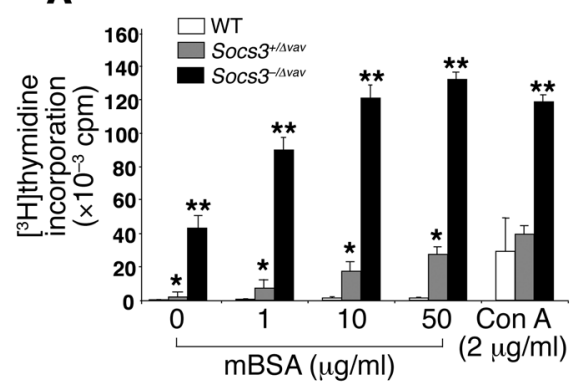

B

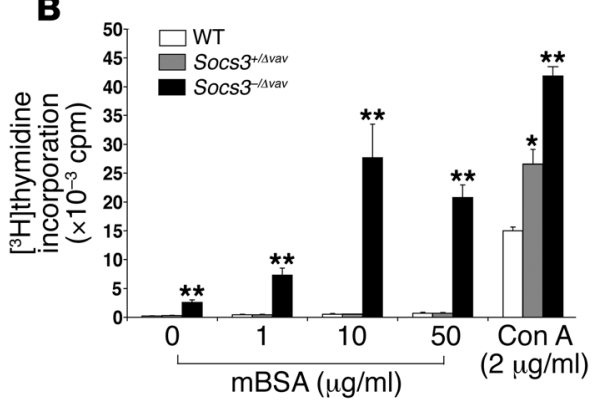

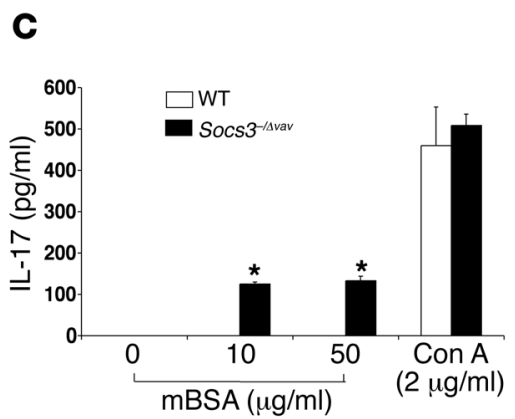

Figure 6

Socs3-/Avav T lymphocytes have markedly enhanced antigen-specific proliferation and IL-17 production in vitro. (A and B) Popliteal (A) and axillary (B) LN cells from arthritic mice were cultured with mBSA for 72 hours, and cellular proliferation was assessed by [ $\left.{ }^{3} \mathrm{H}\right]$ thymidine incorporation. Data are representative of 2 independent experiments. (C) Supernatants were harvested from T lymphocyte cultures after 72 hours of stimulation with $\mathrm{mBSA}$ and assayed for IL-17 by ELISA. IL-17 was undetectable in WT supernatants following mBSA stimulation. ${ }^{*} P<0.05$ versus WT; ${ }^{* \star} P<0.01$ versus WT and Socs3 ${ }^{+/ \Delta v a v}$.

induced arthritis (24). Given that our model is dependent on exogenous IL-1 administration, we investigated whether Socs $3^{-/ \Delta v a v}$ macrophages have enhanced responsiveness to IL-1 stimulation. Socs $3^{-/ \Delta v a v}$ BM-derived macrophages had markedly greater IL-6 production compared with WT and Socs $3^{+/ \Delta v a v}$ macrophages following IL-1 stimulation (Figure 8A).

IL-1 directly induces SOCS-3 expression in macrophages. As Socs $3^{-/ \Delta v a v}$ macrophages were hyperresponsive following IL-1 stimulation, we investigated whether IL- 1 induces SOCS-3 directly in macrophages or indirectly through the production of G-CSF and/or IL-6. To help distinguish between these possibilities, BM macrophages from naive WT, G-CSF-/- and $I L^{-6^{-/-}}$mice were cultured for up to 4 hours in the presence of IL-1, and SOCS-3 expression was determined by real-time PCR. Socs 3 mRNA was rapidly induced in WT macrophages in response to IL-1, with levels peaking at 30 minutes (Figure $8 \mathrm{~B}$ ). This pattern of induction was seen in WT, G-CSF--, and $I L-6^{-/-}$macrophages, suggesting that SOCS- 3 induction was independent of either G-CSF or IL- 6 . The pattern of Socs 3 mRNA induction in response to IL-1 remained unchanged following inhibition of both G-CSF and IL- 6 bioactivity (Figure 8C), excluding the possibility that SOCS-3 was indirectly induced by either of these cytokines following IL-1 stimulation. To ensure that SOCS-3 induction was due to IL-1 and not contaminating bacterial LPS (5), IL-1 was inactivated by boiling. Stimulation with boiled IL-1 reduced SOCS-3 induction in WT macrophages to background levels (data not shown). Taken together, these findings show direct induction of SOCS-3

\section{Figure 7}

Naive Socs3 $3^{-/ \Delta v a v} \mathrm{CD} 4^{+} \mathrm{T}$ lymphocytes are hyperproliferative in vitro. Purified splenic CD4+ $\mathrm{T}$ lymphocytes from naive WT and Socs3-/4vav mice were cultured in the presence of immobilized anti-CD3, rhIL-1, rhG-CSF, and rhIL-6 with sIL-6R, and cellular proliferation was assessed by $\left[{ }^{3} \mathrm{H}\right]$ thymidine incorporation. Supernatants were harvested at 24 hours and assayed for IL-2 by ELISA. Naive Socs3-/Avav CD4+ T lymphocytes had increased proliferation $(\mathbf{A})$ and IL-2 production (B) compared with WT cells following anti-CD3 stimulation. Data are representative of 2 independent experiments. (C) Naive Socs3-/Avav CD4 ${ }^{+} \mathrm{T}$ lymphocytes had increased proliferation in the absence of exogenous cytokine that was further enhanced following addition of each of the cytokines. Data are representative of 3 independent experiments. ${ }^{*} P<0.05$ versus WT. in macrophages by IL-1 rather than indirect induction of SOCS-3 via G-CSF or IL-6 production. However, IL-1 was a less potent inducer of SOCS-3 than was IL-6 (Figure 8D).

\section{Discussion}

To our knowledge, ours is the first study investigating the role of endogenous SOCS-3 in an in vivo model of human disease. Deletion of SOCS-3 in the hematopoietic and endothelial cell compartment was associated with particularly severe IL-1 dependent inflammatory arthritis, characterized by a prominent neutrophil synovial infiltrate and increased osteoclast generation and bone destruction. In naive Socs $3^{-/ \Delta v a v}$ mice, trabecular bone volume was decreased and was associated with increased osteoclastic activity. IL-1 appeared to directly induce SOCS-3 expression in WT macrophages. SOCS-3deficient macrophages overproduced IL-6 following IL-1 stimulation. Arthritis was accompanied by lymphadenopathy in the absence of SOCS-3, with markedly enhanced antigen-specific and mitogenic T lymphocyte responses. Extra-articular features of disease included peripheral neutrophilia, splenomegaly, enhanced granulopoiesis, and elevated systemic levels of G-CSF and IL-6.
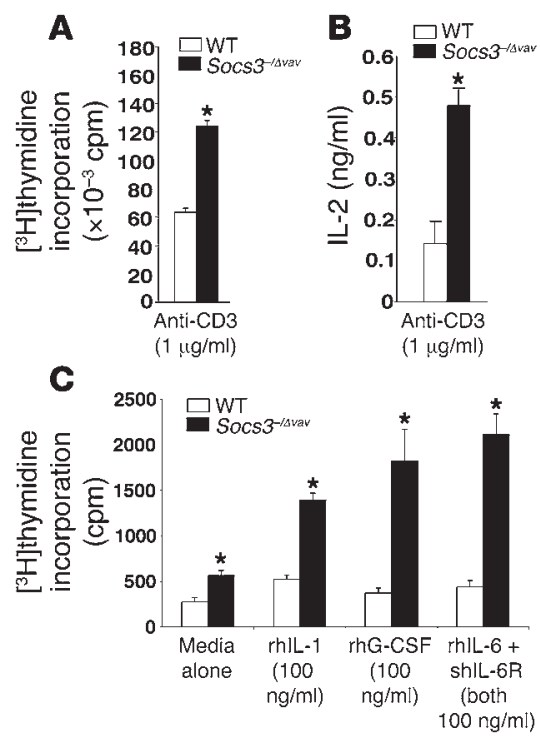

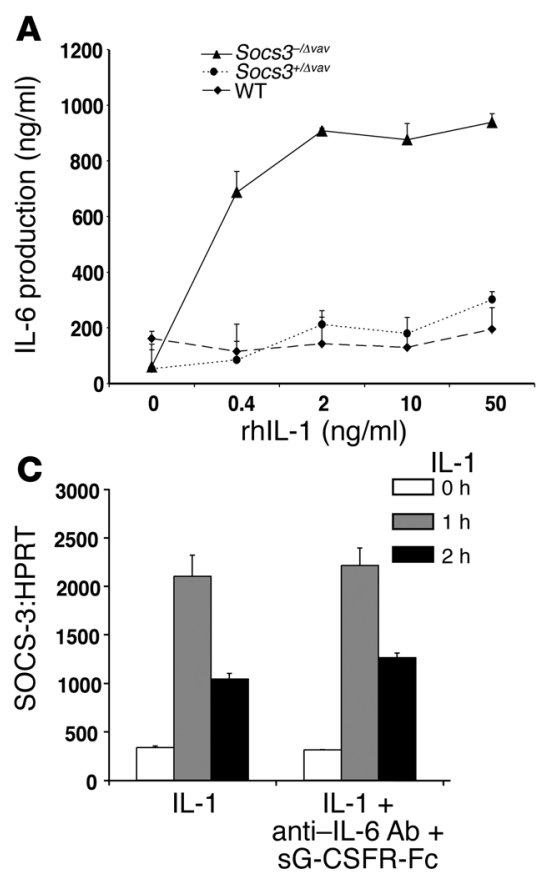

B

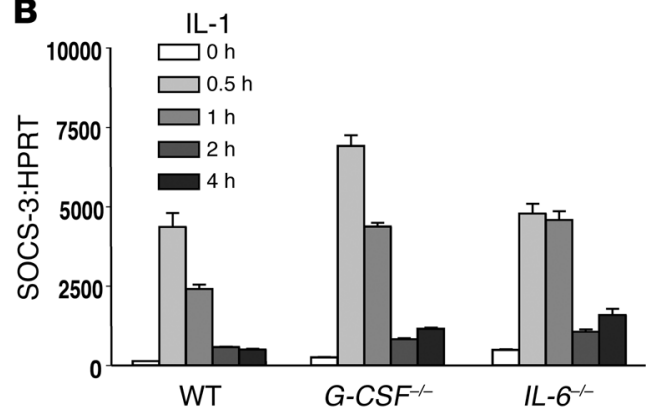

D

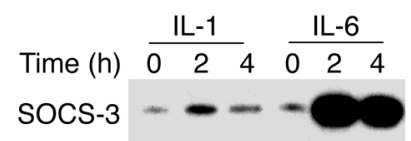

Figure 8

Socs $3^{-/ \Delta v a v}$ macrophages are hyperresponsive to IL-1, and IL-1 induces SOCS-3 directly in WT macrophages. (A) BM macrophages were cultured in the presence of rhlL-1 for 24 hours. Supernatants were harvested and assayed for IL- 6 by ELISA. (B) BM macrophages from naive WT, G-CSF-/-, and $I L-6^{-/-}$mice were cultured with rhlL-1 (100 ng/ml), and expression of SOCS-3 mRNA was determined by real-time PCR. (C) BM macrophages from WT mice were cultured with rhIL-1 in the presence of saturating concentrations of soluble G-CSFR-Fc (sG-CSFR-Fc; $5 \mu \mathrm{g} / \mathrm{ml})$ and an IL-6 $(5 \mu \mathrm{g} / \mathrm{ml})$ neutralizing antibody, and expression of SOCS-3 mRNA was determined by real-time PCR. (D) BM macrophages from naive WT mice were stimulated with rhIL-1 $(100 \mathrm{ng} / \mathrm{ml})$ or recombinant mouse IL-6 $(100 \mathrm{ng} / \mathrm{ml})$ for the indicated times, and the total cellular levels of SOCS-3 were analyzed by immunoprecipitation and Western blot. Similar results were obtained in 2 independent experiments.
Deficiency of SOCS-3 resulted in a qualitatively different inflammatory arthritis to SOCS-1 deficiency in the same disease model (25). There were several distinct features of acute arthritis in Socs $3^{-/ \Delta v a v}$ mice. The most striking difference was that arthritic Socs $3^{-/ \Delta v a v}$ mice had greater numbers of neutrophils in the synovi$\mathrm{um}$, peripheral blood, spleen, and BM, probably due to both neutrophil hyperresponsiveness to G-CSF (16) and elevated systemic levels of G-CSF. When stimulated with G-CSF in vitro, SOCS-3deficient granulocyte lineage cells had enhanced survival and

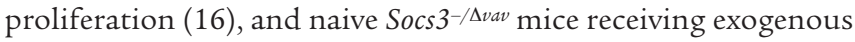
G-CSF developed neutrophilia, progenitor cell mobilization, and splenomegaly (16). Increased numbers of neutrophils entering the joint and undergoing local activation may contribute to joint damage by producing elevated levels of mediators such as oxygen radicals and MMPs (39). Neutrophils can also produce proinflammatory cytokines such as IL-1 (40) and oncostatin M (41). We have recently shown that G-CSF is a critical mediator of inflammatory arthritis (23). A major reason for the severe joint disease in the absence of SOCS-3 may therefore be hypersensitivity of neutrophils and $\mathrm{BM}$ progenitors to G-CSF-induced effects. In contrast, when mBSA/IL-1 arthritis was induced in SOCS-1 $1^{-/-} I F N-\gamma^{-/}$ mice, joint disease was characterized by a monocyte/macrophage synovial infiltrate with prominent granuloma formation but without peripheral neutrophilia or splenomegaly (25). While SOCS-1 promoter activity was found in synovial macrophages, lymphocytes, and fibroblasts during arthritis, it was not detected in synovial granulocytes (25). The predominant cell types at the cartilage-pannus junction in established RA are macrophages and synovial fibroblasts (42). However, neutrophils can also be found at this site, as well as in the joint exudate (39, $43,44)$. These findings suggest that SOCS- 3 and SOCS- 1 have nonredundant functions in regulating myeloid lineage cells and that SOCS-1 may be more important for macrophage responses, whereas SOCS-3 plays a critical role in regulation of neutrophil responses during inflammation.
Several reports have linked SOCS-3 with T lymphocyte activation. SOCS-3 negatively regulated IL-2 signaling $(45,46)$ and bound the phosphatase calcineurin, thereby inhibiting the key transcription factor nuclear factor of activated T cells (47). Binding of SOCS-3 to the PI3K-binding site in CD28 reduced CD28mediated IL-2 production, thereby regulating T helper lymphocyte proliferation (48). Antigenic stimulation of naive T helper lymphocytes downregulated SOCS-3 expression but upregulated SOCS-1 and -2 and cytokine-inducible src homology 2 -containing protein (46), suggesting that SOCS proteins may be differentially regulated by $\mathrm{T}$ lymphocyte activation. As the mBSA/IL-1 model of acute arthritis is dependent on $\mathrm{CD}^{+} \mathrm{T}$ lymphocytes (21) and increased numbers of T lymphocytes were found in draining LNs, we examined $\mathrm{T}$ lymphocyte proliferative responses in $\mathrm{LN}$ of arthritic mice. Both draining and nondraining LN cells from arthritic Socs $3^{-/ \Delta v a v}$ mice exhibited marked antigen-specific $\mathrm{T}$ lymphocyte proliferation. In contrast, while T lymphocytes from draining LNs of arthritic SOCS-1-/-IFN- $\gamma^{-/-}$mice had increased antigen-specific proliferative responses, $\mathrm{T}$ lymphocytes from nondraining LNs did not (25). These findings suggest that SOCS-3 is a critical regulator of antigen-specific T lymphocyte activation and perhaps trafficking. Consistent with these in vivo findings, Socs $3^{-/ \Delta v a v} \mathrm{CD} 4^{+} \mathrm{T}$ lymphocytes were hyperproliferative following stimulation with anti-CD3 antibody in vitro with enhanced IL-2 production.

As naive $\mathrm{T}$ lymphocytes express receptors for both G-CSF (34) and IL-6 (35), we also investigated the effect of IL-1, G-CSF and IL-6 on naive Socs $3^{-/ \Delta v a v} \mathrm{CD} 4^{+} \mathrm{T}$ lymphocytes. Socs $3^{-/ \Delta v a v} \mathrm{CD} 4^{+} \mathrm{T}$ lymphocytes were hyperproliferative following stimulation with each of these cytokines. This suggests that in the absence of SOCS-3, IL-1, IL-6, and G-CSF are able to directly activate bystander CD $4^{+} \mathrm{T}$ lymphocytes. These findings demonstrate that SOCS-3 is a major regulator of $\mathrm{CD}^{+} \mathrm{T}$ lymphocyte activation in response to $\mathrm{T}$ cell receptor engagement and cytokine receptor signaling. Adaptive immune responses are influenced by regulatory $\mathrm{T}$ lymphocyte activity (49). Given the role of IL-6 in overcoming regulatory T 
lymphocyte-mediated suppression (50), it is possible that SOCS-3 may modulate regulatory $\mathrm{T}$ activity by regulating systemic levels of, and responsiveness to, IL-6.

Enhanced biologic responses to IL-6 signaling (12) may contribute to acute inflammatory arthritis through other mechanisms. IL-6 promotes joint destruction through modulation of the balance between MMPs and tissue inhibitor of metalloproteinases at sites of joint inflammation $(51,52)$. While G-CSF is the major regulator of neutrophil production, IL-6 may also contribute to enhanced BM granulopoiesis (32) and peripheral neutrophilia (31). Of interest, the extramedullary hematopoiesis (16) and splenomegaly noted in our arthritic mutant mice were also found in IL-6sIL-6R double transgenic mice (53). While neutrophilia was the most marked peripheral blood abnormality seen in Socs $3^{-/ \Delta v a v}$ mice, thrombocytosis was also noted, possibly due to enhanced IL-6 signaling (54). Given that IL-6 is a B lymphocyte mitogen (55), our finding of increased B lymphocyte accumulation in draining LNs of arthritic Socs $3^{-/ \Delta v a v}$ mice may also be a consequence of enhanced B lymphocyte responsiveness to IL- 6 signaling and elevated IL- 6 levels. Of note, there was no increase in proliferation when purified splenic Socs $3^{-/ \Delta v a v}$ B lymphocytes were cultured in the presence of anti-IgM, LPS, or CD40 ligand (data not shown). However, while IL-6-induced B lymphocyte expansion and cytokine production in draining LNs could contribute to increased disease in the absence of SOCS-3, the generation of $\mathrm{mBSA} / \mathrm{IL}-1$-induced arthritis is independent of B lymphocytes (21).

Osteoclast generation and bone destruction are not typically pronounced in mBSA/IL-1-induced arthritis in WT mice. Osteoclast recruitment in the inflamed joint was not increased in arthritic SOCS $-1^{-/-}$IFN $-\gamma^{-/-}$mice (25). In contrast, the marked inflammatory

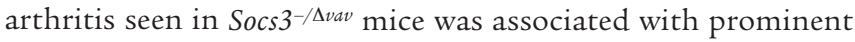
osteoclast generation and bone destruction. There was comparatively more bone than cartilage destruction during mBSA/IL-1induced arthritis in Socs $3^{-/ \Delta v a v}$ mice. This may be because chondro-

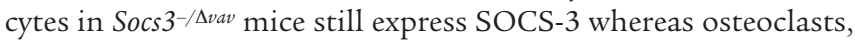
which are derived from hematopoietic precursors (56), lack SOCS-3 following Cre-mediated deletion. T lymphocyte-derived IL-17 appears to be important in the pathogenesis of bone destruction in RA $(57,58)$ by upregulating osteoblast expression of receptor activator of NF- $\kappa \mathrm{B}$ ligand relative to levels of the soluble decoy receptor osteoprotegerin, thereby promoting osteoclastogenesis (59). We found that draining LN T lymphocyte production of IL-17 was increased following antigen-specific proliferation, providing a potential mechanism by which $\mathrm{T}$ lymphocyte activation may have promoted local osteoclastogenesis and bone destruction in Socs3-/4vav mice. IL-17 has also been reported to upregulate G-CSF production by fibroblasts and endothelial cells in vitro $(60,61)$. Transgenic overexpression of G-CSF resulted in increased numbers of BM neutrophils and marked osteoporosis due to osteoclast-mediated bone resorption (62). Another possible mechanism for the enhanced osteoclastogenesis observed in arthritic Socs $3^{-/ \Delta v a v}$ mice may therefore be a combination of increased $\mathrm{T}$ lymphocyte production of IL-17, elevated systemic levels of G-CSF, and enhanced responsiveness to G-CSF signaling.

Osteoclasts have been reported to express SOCS-3 mRNA (7), and overexpression of SOCS-3 in osteoclasts appeared to promote osteoclastogenesis, possibly via suppression of the inhibitory effect of IFN- $\beta$ (7). However, targeting Cre-mediated SOCS-3 deletion to monocytes/macrophages using the LysM promoter (LysM-Cre:Socs $3^{f l f l}$ mice) appeared to have no effect on bone mass and bone density in vivo, at least when compared with Socs $3 f l f l$ mice (63). In contrast, we found that nonarthritic Socs $3^{-/ \Delta v a v}$ mice had enhanced basal osteoclast generation in vivo compared with WT mice. Our findings suggest that endogenous SOCS-3 therefore normally inhibits basal osteoclastogenesis. As osteoblasts are mesenchymally derived (64), Socs $3^{-/ \Delta v a v}$ osteoblasts should express SOCS-3 normally. The enhanced bone formation observed in nonarthritic Socs $3^{-/ \Delta v a v}$ mice is therefore probably a response to increased osteoclastic activity. Dysregulated "coupling" between bone destruction and bone formation most likely explains the $50 \%$ reduction in trabecular bone volume seen in naive Socs $3^{-/ \Delta v a v}$ mice. These findings indicate that endogenous SOCS- 3 regulates osteoclastogenesis and bone turnover.

Macrophages are important cellular mediators in the pathogenesis of inflammatory arthritis due to abundant production of proinflammatory cytokines $(36,65)$. mBSA/IL-1-induced arthritis requires synovial macrophages $(24)$. We found enhanced macrophage IL- 6 production following IL-1 stimulation in the absence of SOCS-3. Hence activated macrophages in the synovium or possibly in the hematopoietic tissues are most likely responsible for the elevated systemic levels of IL- 6 observed. IL- 6 has been shown to be a potent inducer of macrophage and osteoclast differentiation $(66,67)$. SOCS-3 is therefore important in the regulation of macrophage responses, and dysregulated synovial macrophage function may contribute to enhanced inflammatory arthritis.

It is unclear from previous literature whether SOCS-3 is directly induced by IL- 1 in a physiologically relevant time frame $(68,69)$. We found that within 30 minutes of stimulation with IL-1, SOCS-3 mRNA was detected in WT macrophages. Production of SOCS-3 protein in response to IL-1 peaked at 2 hours. This pattern of SOCS-3 induction persisted in $\mathrm{G}-\mathrm{CSF}^{-/-}$and $\mathrm{IL}^{-6^{-/-}}$macrophages and in WT macrophages following neutralization of both G-CSF and IL- 6 bioactivity. We were careful to exclude any effect on SOCS-3 expression from contaminating LPS, as this is a potent inducer of SOCS-3 via Toll-like receptor activation $(5,70)$. These findings strongly suggest that IL-1 directly induces SOCS-3 in macrophages and raise the possibility that SOCS-3 may negatively regulate IL-1 signaling. However, we found that IL-1 was a less potent inducer of SOCS-3 in macrophages than IL-6.

Deletion of SOCS-3 resulted in markedly exacerbated IL-1dependent arthritis and increased systemic G-CSF and IL-6. In vitro, IL-6 induced expression of IFN- $\gamma$-responsive genes in both hepatocytes (12) and macrophages (13) lacking SOCS-3, and it was hypothesized this might result in immunosuppressive effects (14). IL-6 also attenuated LPS-induced TNF production in macrophages lacking SOCS-3 in vitro, and LysM-Cre:Socs $3^{f l / f l}$ mice were protected against LPS-induced endotoxic shock in vivo, raising the possibility that in the absence of SOCS-3, IL- 6 may induce an IL-10like antiinflammatory effect (15). Whilst we have previously shown that IFN- $\gamma$ is dispensable for peak disease severity in mBSA/IL-1induced arthritis in WT mice (25), this does not exclude the possibility that IL- 6 -induced IFN- $\gamma$ could have antiinflammatory effects in the absence of SOCS-3 (14). However, our findings clearly show that in vivo, the absence of SOCS-3 is profoundly proinflammatory in this model of acute arthritis.

Our data implicate SOCS-3 as a critical negative regulator of IL-1dependent acute inflammatory arthritis. SOCS-3 appeared to regulate responses in a wider range of hematopoietic cell types than SOCS-1. Unlike SOCS-1, SOCS-3 may regulate the G-CSF-driven neutrophil response in acute arthritis, thereby contributing to 
exacerbated disease. Macrophage cytokine production and osteoclast generation were markedly enhanced in the absence of SOCS-3. Enhanced T lymphocyte activation in the absence of SOCS-3 may drive disease and also promote osteoclastogenesis by upregulating IL-17 production. SOCS-3 therefore appears to be a potent negative regulator of multiple proinflammatory pathways in joint disease. Our findings raise the possibility that pharmacologic manipulation of SOCS-3 may have a role in the treatment of inflammatory arthritis and other systemic inflammatory diseases.

\section{Methods}

Mice. A conditional gene-targeting approach was used to study the role of SOCS-3 in vivo. Socs $3^{-/ \Delta v a v}$ mice, in which SOCS-3 was deleted in all hematopoietic and endothelial cell lineages, have been previously described (16). All mice were aged between 8 and 12 weeks at time of experimentation to avoid the previously described age-related dysregulation of hematopoiesis (16). WT C57BL/6 mice, obtained from Walter and Eliza Hall Institute Animal Services, and Socs $3^{+/ \Delta v a v}$ mice were used as controls. $I L-6^{-/-}$and $G$-CSF ${ }^{-1}$ mice were generated as previously described $(28,71)$. All animal procedures were approved by the Animal Ethics Committee of Melbourne Health, Parkville, Australia.

Induction of acute inflammatory arthritis with $\mathrm{mBSA}$ and IL-1. Induction of acute arthritis was performed as previously described (21). Briefly, adult mice were anesthetized and injected IA with $10 \mu \mathrm{l}$ of a $20 \mathrm{mg} / \mathrm{ml}$ solution of mBSA (endotoxin level, < $1 \mathrm{pg} / \mu \mathrm{g}$; Sigma-Aldrich) into knee joints. Mice were then injected with $20 \mu \mathrm{l}$ of $12.5 \mu \mathrm{g} / \mathrm{ml}$ recombinant human IL-1 $\beta$ (rhIL-1 $\beta$; endotoxin level, $<0.1 \mathrm{ng} / \mu \mathrm{g}$; PeproTech) in the footpad. This was repeated for the next 2 days.

Histologic assessment of $m B S A / I L-1-i n d u c e d$ arthritis. Mice were euthanized on day 7 following IA mBSA injection, and the knee joints were removed and processed as described previously (21). Severity of arthritis was assessed using 5 histologic features of joint disease (exudate, synovitis, pannus, cartilage, and bone destruction), each graded for severity from 0 (normal) to 5 (severe) by an investigator blinded to the experimental groups as previously described (21). The overall mean histologic severity score for an experimental group (maximum of 25) was calculated by averaging the sum of the 5 histologic features, with each feature scored at 4 section depths. When assessing cartilage destruction, proteoglycan loss was also scored from 0 to 5 on Safranin O-stained sections.

Histomorphometry. Tibiae were collected from 8- to 12-week-old mice, fixed in $4 \%$ paraformaldehyde in PBS, and embedded in methylmethacrylate (72). Histomorphometry was performed with the Osteomeasure system (OsteoMetrics Inc.) as previously described (72). The following parameters were calculated from the proximal tibia: trabecular bone volume, ratio of osteoclast surface to bone surface, and ratio of osteoblast surface to bone surface.

TRAP. TRAP was performed according to the manufacturer's instructions (Sigma-Aldrich) on knee joint sections from arthritic mice fixed in $4 \%$ paraformaldehyde in PBS and demineralized in EDTA as described previously (73). The number of $\mathrm{TRAP}^{+}$cells on the joint periosteal surfaces was counted by an investigator blinded to the experimental groups.

Isolation of cells from synovial tissue. Synovial tissue was dissected from knee joints of arthritic mice and digested in a cocktail of $2.4 \mathrm{mg} / \mathrm{ml}$ dispase (Boehringer Mannheim), $1 \mathrm{mg} / \mathrm{ml}$ collagenase (Sigma-Aldrich), and $100 \mu \mathrm{g} / \mathrm{ml}$ DNase I (Boehringer Mannheim) in RPMI for 1 hour at $37^{\circ} \mathrm{C}$ as previously described (25). Cells were then filtered, washed, and stained for flow cytometric analysis.

Flow cytometry and differential blood counts. LN, spleen, and BM cells were stained for flow cytometric analysis using FITC- or PE-conjugated antibodies to CD8 $\alpha$ (clone CT-CD8a), CD11b (clone M1/70), B220 (clone RA3-6B2) and CD4 (clone CT-CD4; all from CALTAG Laboratories). Biotinylated antibodies to CD45.2 (clone 104) and GR-1 (clone RB6-8C5) were obtained from BD Biosciences - Pharmingen. Nonspecific binding of antibodies was blocked by preincubation of cells with an antibody to CD16 and CD32 (clone 2.4G2), and biotinylated antibodies were detected using streptavidinTriColor (CALTAG Laboratories). Cells were analyzed on a FACScan flow cytometer using CellQuest software version 3.3 (BD Immunocytometry Systems). Peripheral blood from arthritic mice was collected and analyzed on an Advia 120 automatic cell analyzer (Bayer Diagnostics).

LN cell proliferation assays. Draining (popliteal and inguinal) and nondraining (axillary) LN cells of arthritic mice were cultured in 96-well plates $\left(4 \times 10^{5}\right.$ cells/well) in $200 \mu \mathrm{l}$ RPMI supplemented with $10 \%$ FCS (Trace Biosciences) and $50 \mu \mathrm{M} 2$-mercaptoethanol (T lymphocyte medium). Cultures were performed at $37^{\circ} \mathrm{C}\left(5 \% \mathrm{CO}_{2}\right)$ for 72 hours with $0-50 \mu \mathrm{g} / \mathrm{ml} \mathrm{mBSA}$ or $2 \mu \mathrm{g} / \mathrm{ml}$ Con A and pulsed with $\left[{ }^{3} \mathrm{H}\right]$ thymidine $(1 \mu \mathrm{Ci} /$ well; Amersham Biosciences) during the last 8 hours of incubation before harvesting with an Inotech Biosystems cell harvester. $\left[{ }^{3} \mathrm{H}\right]$ thymidine incorporation was determined on a microplate scintillation counter (CANBERRA).

$\mathrm{CD}^{+} \mathrm{T}$ lymphocyte proliferation assays. $\mathrm{CD}^{+} \mathrm{T}$ lymphocytes were isolated from spleens by staining with CD4-FITC and anti-FITC microbeads (Miltenyi Biotec). CD4 ${ }^{+} \mathrm{T}$ lymphocytes were positively selected using an AutoMACS according to the manufacturer's instructions (Miltenyi Biotec) and resuspended in Tlymphocyte medium at $1 \times 10^{5}$ cells $/ 100 \mu$ in 96 -well plates. Cell purity was determined by flow cytometry. Cells were cultured at $37^{\circ} \mathrm{C}\left(5 \% \mathrm{CO}_{2}\right)$ for 24 hours in the presence of plate-bound anti-CD3 antibody $(1 \mu \mathrm{g} / \mathrm{ml}$; clone $1452 \mathrm{C} 11)$ and the following cytokines, all at $100 \mathrm{ng} / \mathrm{ml}$ : rhIL-1, rhG-CSF (lenograstim; Amgen Inc.), and rhIL-6 with sIL-6R (both from PeproTech).

$I L-2, I L-6, I L-17$, and G-CSF ELISAs. Cytokine ELISAs were performed using the appropriate matched antibodies (BD Pharmingen or R\&D Systems). Optical density at $450 \mathrm{~nm}$ was read on a Multiscan Ascent ELISA Reader (Thermo Electron Corp.).

Macrophage cultures. BM-derived macrophages were prepared by culturing BM cells in M-CSF $\left(10 \mathrm{ng} / \mathrm{ml}\right.$; R\&D Systems) for 6 days. WT, Socs $3^{+/ \Delta v a v}$, and Socs $3^{-/ \Delta v a v}$ macrophages $\left(5 \times 10^{5} \mathrm{cells} / \mathrm{ml}\right)$ were cultured overnight and stimulated with rhIL-1 $(0-50 \mathrm{ng} / \mathrm{ml})$ for 24 hours. Supernatants were assayed for IL- 6 by ELISA. WT, IL-6 $6^{--}$, and $\mathrm{G}^{-} \mathrm{CSF}^{-/-} \mathrm{BM}$ macrophages were stimulated with rhIL-1 (100 ng/ml) for 0-4 hours, and WT macrophages were cultured under these conditions in the presence of a saturating concentration of soluble G-CSFR-Fc $(5 \mu \mathrm{g} / \mathrm{ml})$ and a neutralizing antibody directed against IL-6 (5 $\mu \mathrm{g} / \mathrm{ml}$, clone MP5-20F3; BD Biosciences - Pharmingen). cDNA sequence coding for the extracellular domain of the murine G-CSF receptor was ligated to the coding region of human $\operatorname{IgG} 1 \mathrm{Fc}$, and the expression construct was transfected into CHO cells. Soluble G-CSF receptor fusion protein was purified from conditioned cell medium by protein $\mathrm{G}$ purification and was used at a concentration of $5 \mu \mathrm{g} / \mathrm{ml}$.

Real-time PCR. Total RNA was isolated from BM-derived macrophages stimulated with rhIL-1, and cDNA for real-time PCR was generated as previously described (16). Expression of Socs 3 was quantified by comparison with expression of the housekeeping gene Hprt using primer sequences as described previously (16).

Immunoblotting. Macrophages $\left(1.5 \times 10^{7}\right.$ per $15-\mathrm{cm}$ dish $)$ derived from $\mathrm{BM}$ of naive WT mice were allowed to adhere overnight in DMEM supplemented with $15 \%$ FCS and M-CSF $\left(10^{3} \mathrm{U} / \mathrm{ml}\right)$, after which exogenous M-CSF was removed for 2 hours and cells were stimulated with rhIL-1 $(100 \mathrm{ng} / \mathrm{ml})$ or recombinant mouse IL-6 (100 ng/ml) for 2 or 4 hours. Cells were lysed in KALB lysis buffer (1 mM EDTA, $150 \mathrm{mM} \mathrm{NaCl}, 50 \mathrm{mM}$ Tris-Cl, $1 \%$ Triton $\mathrm{X}-100, \mathrm{pH} 7.5$ ), and SOCS-3 was immunoprecipitated from the cell extract using a mouse monoclonal antibody (clone 1B2). Immunoprecipitates were subjected to SDS-PAGE, and total cellular levels $\left(1.5 \times 10^{7}\right.$ cells $)$ of 
SOCS-3 were visualized using a rabbit polyclonal antibody to SOCS-3 (C-204; Immuno-Biological Laboratories Co. Ltd.).

Statistics. Differences in mean $\left[{ }^{3} \mathrm{H}\right]$ thymidine incorporation and arthritis histologic scores between groups were assessed by Student's 2-tailed $t$ test and the Wilcoxon rank sum test, respectively. A $P$ value less than 0.05 was considered significant.

Note added in proof. Using an overexpression system, Frobose et al. have recently shown that SOCS-3 inhibited IL-1 signaling by targeting the association between TRAF6 and TAK1 (74). These findings support the hypothesis that SOCS-3 can negatively regulate IL-1 signaling.

\section{Acknowledgments}

This work was supported by the Reid Charitable Trusts, Arthritis Australia, the National Health and Medical Research Council of Australia (program grant 257500 and project grant 305523), the National Institutes of Health (grant CA22556) and AMRAD Operations Pty. Ltd. We thank A. Dunn (Ludwig Institute for Cancer Research, Parkville, Victoria, Australia) for provision of G-CSF $-/-$ mice; S. Mihajlovic and E. Tsui for histology; and J. Merryfull, J. Morrow, and G. Panoschi for animal husbandry.

Received for publication May 17, 2005, and accepted in revised form March 28, 2006.

Address correspondence to: Ian P. Wicks, Reid Rheumatology Laboratory, Division of Autoimmunity and Transplantation, Walter and Eliza Hall Institute, 1G Royal Parade, Parkville, Victoria 3050, Australia. Phone: 61-3-9345-2466; Fax: 61-3-9347-0852; E-mail: wicks@wehi.edu.au.

Paul J. Egan and Ben A. Croker contributed equally to this work.
1. Smolen, J.S., and Steiner, G. 2003. Therapeutic strategies for rheumatoid arthritis. Nat. Rev. Drug Discov. 2:473-488.

2. Arend, W.P. 2002. The balance between IL-1 and IL-1Ra in disease. Cytokine Growth Factor Rev. 13:323-340.

3. Feldmann, M. 2002. Development of anti-TNF therapy for rheumatoid arthritis. Nat. Rev. Immunol. 2:364-371.

4. Alexander, W.S. 2002. Suppressors of cytokine signalling (SOCS) in the immune system. Nat. Rev. Immunol. 2:1-7.

5. Bode, J.G., et al. 1999. LPS and TNF $\alpha$ induce SOCS3 mRNA and inhibit IL-6-induced activation of STAT3 in macrophages. FEBS Lett. 463:365-370.

6. Starr, R., et al. 1997. A family of cytokine-inducible inhibitors of signalling. Nature. 387:917-921.

7. Fox, S.W., Haque, S.J., Lovibund, A.C., and Chambers, T.J. 2003. The possible role of TGF- $\beta$-induced suppressors of cytokine signaling expression in osteoclast/macrophage lineage commitment in vitro. J. Immunol. 170:3679-3687.

8. Starr, R., et al. 1998. Liver degeneration and lymphoid deficiencies in mice lacking suppressor of cytokine signaling-1. Proc. Natl. Acad. Sci. U. S. A. 95:14395-14399.

9. Alexander, W.S., et al. 1999. SOCS1 is a critical inhibitor of interferon $\gamma$ signaling and prevents the potentially fatal neonatal actions of this cytokine. Cell. 98:597-608.

10. Marine, J.C., et al. 1999. SOCS3 is essential in the regulation of fetal liver erythropoiesis. Cell. 98:617-627.

11. Roberts, A.W., et al. 2001. Placental defects and embryonic lethality in mice lacking suppressor of cytokine signaling 3. Proc. Natl. Acad. Sci. U. S. A. 98:9324-9329.

12. Croker, B.A., et al. 2003. SOCS3 negatively regulates IL-6 signaling in vivo. Nat. Immunol. 4:540-545.

13. Lang, R., et al. 2003. SOCS3 regulates the plasticity of gp130 signaling. Nat. Immunol. 4:546-550.

14. Johnston, J.A., and O'Shea, J.J. 2003. Matching SOCS with function. Nat. Immunol. 4:507-509.

15. Yasukawa, H., et al. 2003. IL-6 induces an antiinflammatory response in the absence of SOCS3 in macrophages. Nat. Immunol. 4:551-556.

16. Croker, B.A., et al. 2004. SOCS3 is a critical physiological negative regulator of G-CSF signaling and emergency granulopoiesis. Immunity. 20:1-20.

17. Atsumi, T., et al. 2002. A point mutation of Tyr-759 in interleukin- 6 family cytokine receptor subunit gp130 causes autoimmune arthritis. J. Exp. Med. 196:979-990.

18. Ernst, M., et al. 2001. Defective gp130-mediated signal transducer and activator of transcription (STAT) signaling results in degenerative joint disease, gastrointestinal ulceration, and failure of uterine implantation. J. Exp. Med. 194:189-203.

19. Shouda, T., et al. 2001. Induction of the cytokine signal regulator SOCS3/CIS as a therapeutic strategy for treating inflammatory arthritis. J. Clin. Invest. 108:1781-1788. doi:10.1172/JCI200113568.

20. Campbell, I.K., Gerondakis, S., O'Donnell, K., and Wicks, I.P. 2000. Distinct roles for the NFKB1(p50) and c-Rel transcription factors in inflammatory arthritis. J. Clin. Invest. 105:1799-1806.

21. Lawlor, K.E., Campbell, I.K., Li, W., O’Donnell, K., and Wicks, I.P. 2001. Molecular and cellular mediators of acute IL-1-dependent arthritis. Arthritis Rheum. 44:442-450.

22. Dinarello, C.A. 2005. Blocking IL-1 in systemic inflammation. J. Exp. Med. 201:1355-1359.

23. Lawlor, K.E., et al. 2004. Critical role for granulocyte colony-stimulating factor in inflammatory arthritis. Proc. Natl. Acad. Sci. U. S. A. 101:11398-11403.

24. Lawlor, K.E., Wong, P.K., Campbell, I.K., van Rooijen, N., and Wicks, I.P. 2005. Acute CD4+ T lymphocyte-dependent interleukin-1-driven arthritis selectively requires interleukin- 2 and interleukin-4, joint macrophages, granulocyte-macrophage colony-stimulating factor, interleukin- 6 and leukemia inhibitory factor. Arthritis Rheum. 52:3749-3754.

25. Egan, P.J., Lawlor, K.E., Alexander, W.S., and Wicks, I.P. 2003. Suppressor of cytokine signaling-1 regulates acute inflammatory arthritis and $\mathrm{T}$ cell activation. J. Clin. Invest. 111:915-924. doi:10.1172/ JCI200316156.

26. Campbell, I.K., O’Donnell, K., Lawlor, K.E., and Wicks, I.P. 2001. Severe inflammatory arthritis and lymphadenopathy in the absence of TNF. J. Clin. Invest. 107:1519-1527.

27. Sims, N.A., et al. 2002. Deletion of estrogen receptors reveals a regulatory role for estrogen receptors-beta in bone remodeling in females but not in males. Bone. 30:18-25.

28. Lieschke, G.J., et al. 1994. Mice lacking granulocyte colony-stimulating factor have chronic neutropenia, granulocyte and macrophage progenitor cell deficiency, and impaired neutrophil mobilization. Blood. 84:1737-1746.

29. Metcalf, D. 1998. The molecular control of hematopoiesis: progress and problems with gene manipulation. Stem Cells. 16:1-9.

30. Roberts, A. 2005. G-CSF: a key regulator of neutrophil production, but that's not all! Growth Factors. 23:33-41.

31. Ulich, T.R., del Castillo, J., and Guo, K.Z. 1989. In vivo hematologic effects of recombinant interleukin- 6 on hematopoiesis and numbers of RBCs and WBCs. Blood. 73:108-110.

32. Kitamura, H., et al. 1995. Bone marrow neutrophilia and suppressed bone turnover in human interleukin-6 transgenic mice. Am. J. Pathol. 147:1682-1692.
33. Kotake, S., et al. 2001. Activated human T cells directly induce osteoclastogenesis from human monocytes: possible role of T cells in bone destruction in rheumatoid arthritis patients. Arthritis Rheum. 44:1003-1012.

34. Franzke, A., et al. 2003. G-CSF as immune regulator in T cells expressing the G-CSF receptor: implications for transplantation and autoimmune diseases. Blood. 102:734-739.

35. Teague, T.K., et al. 2000. Activation-induced inhibition of interleukin 6-mediated T cell survival and signal transducer and activator of transcription 1 signaling. J. Exp. Med. 191:915-926.

36. Brennan, F.M., and Foey, A.D. 2002. Cytokine regulation in RA synovial tissue: role of T cell/macrophage contact-dependent interactions. Arthritis Res. 4:S177-S182.

37. Aarden, L., de Groot, E., Schaap, O., and Landsdorp, P. 1987. Production of hybridoma growth factor by human monocytes. Eur. J. Immunol. 17:1411-1416.

38. Demetri, G., and Griffin, J. 1991. Granulocyte colony-stimulating factor and its receptor. Blood. 78:2791-2808.

39. Pillinger, M.H., and Abramson, S.B. 1995. The neutrophil in rheumatoid arthritis. Rheum. Dis. Clin. North Am. 21:691-714.

40. Quayle, J.A., Adams, S., Bucknall, R.C., and Edwards, S.W. 1995. Interleukin-1 expression by neutrophils in rheumatoid arthritis. Ann. Rheum. Dis. 54:930-933.

41. Cross, A., Edwards, S.W., Bucknall, R.C., and Moots, R.J. 2004. Secretion of oncostatin M by neutrophils in rheumatoid arthritis. Arthritis Rheum. 50:1430-1436.

42. Bromley, M., and Woolley, D.E. 1984. Histopathology of the rheumatoid lesion. Identification of cell types at sites of cartilage erosion. Arthritis Rheum. 27:857-863.

43. Mohr, W., and Menninger, H. 1980. Polymorphonuclear granulocytes at the pannus-cartilage junction in rheumatoid arthritis. Arthritis Rheum. 23:1413-1414.

44. Mohr, W., Westerhellweg, H., and Wessinghage, D. 1981. Polymorphonuclear granulocytes in rheumatic tissue destruction. III. An electron microscopic study of PMNs at the pannus-cartilage junction in rheumatoid arthritis. Ann. Rheum. Dis. 40:396-399.

45. Cohney, S.J., et al. 1999. SOCS-3 is tyrosine phosphorylated in response to interleukin-2 and suppresses STAT5 phosphorylation and lymphocyte proliferation. Mol. Cell. Biol. 19:4980-4988.

46. Yu, C.R., et al. 2003. Suppressor of cytokine signaling 3 regulates proliferation and activation of Thelper cells. J. Biol. Chem. 22:29752-29759.

47. Banerjee, A., Banks, A.S., Nawijn, M.C., Chen, X.P., 
and Rothman, P.B. 2002. Cutting edge: suppressor of cytokine signaling 3 inhibits activation of NFATp. J. Immunol. 168:4277-4281.

48. Matsumoto, A., et al. 2003. A role of suppressor of cytokine signaling 3 (SOCS/CIS3/SSI3) in CD28 mediated interleukin-2 production. J. Exp. Med. 197:425-436

49. Powrie, F., and Maloy, K. 2003. Regulating the regulators. Science. 299:1030-1031.

50. Pasare, C., and Medzhitov, R. 2003. Toll pathway-dependent blockade of CD4+CD25+ T cellmediated suppression by dendritic cells. Science. 299:1033-1036.

51. Ito, A., Itoh, Y., Sasaguri, Y., Morimatsu, M., and Mori, Y. 1992. Effects of interleukin-6 on the metabolism of connective tissue components in rheumatoid synovial fibroblasts. Arthritis Rheum. 35:1197-1201.

52. Roux-Lombard, P., Eberhardt, K., Saxne, T., Dayer, J.M., and Wollheim, F.A. 2001. Cytokines, metalloproteinases, their inhibitors and cartilage oligomeric matrix protein: relationship to radiological progression and inflammation in early rheumatoid arthritis. A prospective 5-year study. Rheumatology (Oxford). 40:544-551.

53. Peters, M., et al. 1997. Extramedullary expansion of hematopoietic progenitor cells in interleukin(IL)6-sIL-6R double transgenic mice. J. Exp. Med. 185:755-766.

54. Asano, S., et al. 1990. In vivo effects of recombinant human interleukin-6 in primates: stimulated production of platelets. Blood. 75:1602-1605.

55. Van Damme, J., et al. 1987. Identification of the human $26-\mathrm{kD}$ protein, interferon beta 2 (IFN-beta 2 ), as a B cell hybridoma/plasmacytoma growth factor induced by interleukin 1 and tumor necrosis factor. J. Exp. Med. 165:914-919.
56. Teitelbaum, S.L. 2000. Bone resorption by osteoclasts. Science. 289:1504-1508.

57. Lubberts, E., et al. 2003. IL-17 promotes bone erosion in murine collagen-induced arthritis through loss of the receptor activator of NF-kappa B ligand/osteoprotegerin balance. J. Immunol. 170:2655-2662.

58. Miossec, P. 2003. Interleukin-17 in rheumatoid arthritis. Arthritis Rheum. 48:594-601.

59. Kotake, S., et al. 1999. IL-17 in synovial fluids from patients with rheumatoid arthritis is a potent stimulator of osteoclastogenesis. J. Clin. Invest. 103:1345-1352.

60. Cai, X.Y., Gommoll, C.P.J., Justice, L., Narula, S.K., and Fine, J.S. 1998. Regulation of granulocyte colony-stimulating factor gene expression by interleukin-17. Immunol. Lett. 62:51-58.

61. Jones, C.E., and Chan, K. 2002. Interleukin-17 stimulates the expression of interleukin-8, growthrelated oncogene-alpha, and granulocyte-colonystimulating factor by human airway epithelial cells. Am. J. Respir. Cell Mol. Biol. 26:748-753.

62. Takahashi, T., Wada, T., Mori, M., Kokai, Y., and Ishii, S. 1996. Overexpression of the granulocytecolony stimulating factor leads to osteoporosis in mice. Lab. Invest. 74:827-834.

63. Ohishi, M., et al. 2005. Suppressors of cytokine signaling- 1 and -3 regulate osteoclastogenesis in the presence of inflammatory cytokines. J. Immunol. 174:3024-3031.

64. Ducy, P., Schinke, T., and Karsenty, G. 2000. The osteoblast: a sophisticated fibroblast under central surveillance. Science. 289:1501-1504.

65. Firestein, G.S., et al. 1988. Cytokines in chronic inflammatory arthritis. I. Failure to detect $\mathrm{T}$ cell lymphokines (interleukin 2 and interleukin 3) and presence of macrophage colony-stimulating fac- tor (CSF-1) and a novel mast cell growth factor in rheumatoid synovitis. J. Exp. Med. 168:1573-1586.

66. Nicola, N., Metcalf, D., Matsumoto, M., and Johnson, G.R. 1983. Purification of a factor inducing differentiation in murine myelomonocytic leukemia cells. J. Biol. Chem. 258:9017-9023.

67. Tamura, T., et al. 1993. Soluble interleukin- 6 receptor triggers osteoclast formation by interleukin-6. Proc. Natl. Acad. Sci. U. S. A. 90:11924-11928.

68. Boisclair, Y.R., Wang, J., Shi, J., Hurst, K.R., and Ooi, G.T. 2000. Role of the suppressor of cytokine signaling-3 in mediating the inhibitory effects of interleukin- $1 \beta$ on the growth hormone-dependent transcription of the acid-labile subunit gene in liver cells. J. Biol. Chem. 275:3841-3847.

69. Karlsen, A.E., et al. 2001. Suppressor of cytokine signaling 3 (SOCS-3) protects $\beta$-cells against interleukin-1 $\beta$ - and interferon- $\gamma$ mediated toxicity. Proc. Natl. Acad. Sci. U. S. A. 98:12191-12196.

70. Yoshimura, A., Mori, H., Ohishi, M., Aki, D., and Hanada, T. 2004. Regulation of TLR signaling and inflammation by SOCS family proteins. J. Leukoc. Biol. 75:422-427.

71. Kopf, M., et al. 1994. Impaired immune and acutephase responses in interleukin-6-deficient mice. Nature. 368:339-342.

72. Sims, N.A., et al. 2000. Bone homeostasis in growth hormone receptor-null mice is restored by IGF-I but independent of Stat5. J. Clin. Invest. 106:1095-1103.

73. Jonsson, R., Tarkowski, A., and Klareskog, L. 1986. A demineralization procedure for immunohistopathological use: EDTA treatment preserves lymphoid cell surface antigens. J. Immunol. Methods. 88:109-114.

74. Frobose, H., et al. 2006. Suppressor of cytokine signaling (SOCS)-3 inhibits IL-1 signaling by targeting the TRAF-6/TAK1 complex. Mol. Endocrinol. doi:10.1210/me.2005-0301. 